\title{
One Experience is Worth a Thousand Words: Engaging Undergraduates in Field Research on Gender
}

\author{
Cindy Simon Rosenthal, University of Oklahoma
}

In teaching about women in politics and public administration, I have encountered two reactions most common among undergraduatesavoidance and resistence. Avoidance prevents many undergraduates from considering a course with the words "gender" or "women" or "sex" in the title. "That's not for me" responded a young man, who, while enthusiastic about my course on state government, had little stomach for a course entitled "Gender, Power and Leadership." Even though a few young men end up in my classroom at the urging of their mothers, spouses, or "significant others," I have yet to discover an effective way of overcoming the avoidance that keeps some students from enrolling in courses that use gender as a conceptual framework.

Once in the classroom, many students refuse to accept that gender has the potential to shape life opportunities and experiences in profoundly different ways for men and women. In part, their resistence reflects the conservative trend in political attitudes over the past decade, which leads many undergraduates to reject the language of feminism and question its usefulness for describing what they experience in their own lives (Fox-Genovese 1996). While espousing liberal feminist values of equality, today's students often reject many aspects of the feminist agenda, such as critiquing patriarchy, and tend to locate concerns about, for instance, work-place dis-

Cindy Simon Rosenthal is assistant professor of political science at the University of Oklahoma and assistant director of the Carl Albert Congressional Research and Studies Center. crimination or sexism in a bygone era.

Two problems reinforce (and seemingly affirm) student resistance. First, although masculinity is the principle ideology informing politics, its presence goes mostly unremarked and its influence remains largely unanalyzed, which serves to hide gender as a conceptually powerful tool for studying politics. As DuerstLahti and Kelly concluded, "Gender's invisibility in the realm of leadership and governance lies in masculine assumptions" $(1995,26)$. Second, because most enterprises and institution are gendered, organizations are experienced differently by women and men (Kenney 1996, 456). Those who do not "experience" the institutions directly often find it easy to reject the argument that gender shapes the processes, procedures and cultures of organizations.

Both the popular and scholarly literature on the experiences of women in politics or public service speak most directly to students who have some personal experience with issues of work place discrimination or differential treatment that exist as a result of the unspoken masculinity of many institutions. In my classes about women in politics, the students typically divide between traditional undergraduates (i.e., unmarried twenty-something men and women), whose faith in the equality of political life is undaunted, and older women, whose work, marital, and social experiences-"been there and done that"- - have shaken their fundamental optimism about the equality of women and men.

Resistence to using gender as an analytical framework manifests itself in two primary ways: oppositional position-taking in classroom discussions and preemptory rejection of gender concepts. Regardless of one's perspective on whether or not a "backlash" has occurred against the feminist movement (Faludi 1991), the emergence of various men's movements including profeminist and promasculinist groups, the fragmentation of feminist voices, and the increasing political and cultural power of conservative groups espousing "traditional" family values have helped ensure that our cultural conversation about gender is more of a cacophony than a dialogue. Gendered stereotypes add rigidity to communication about gender in organizational life (Wood 1994, 26178), and an "argument culture" encourages more debate than understanding of different perspectives (Tannen 1998). The challenge for the instructor wishing to have students engage gender, then, is to promote dialogue where division and opposition predominate. Experiential learning offers a successful strategy for promoting more thoughtful and less divisive discussion and is, consequently, a useful curriculum strategy for dealing with student resistence.

In the spring of 1997 , as a component of "Gender, Power and Leadership," I developed an experiential learning strategy and field research project as a means of transforming students' gender understandings from abstractions into concrete lessons. The project engaged undergraduate students in the research process from development of hypotheses through the interpretation 
of data collected in field interviews. In this article, I describe the strategy, report student response, and draw lessons from the experience.

\section{The Literature on Experiential Learning}

Experiential learning has been promoted as a key to making education more relevant to diverse student populations and as a strategy for matching different student learning styles to complex subject matters (Kolb 1984). Kolb defined experiential learning as a "holistic integrative perspective on learning that combines experience, perception, cognition, and behavior" (21), and identified four essential stages in the cycle: concrete experience, reflective observation, abstract conceptualization, and active experimentation. Kolb argued that learning represents a "continuous process grounded in experience," during which knowledge grows as new information and experiences are assimilated. Kolb's work also recognizes that varied classroom activities help to reach different types of students. Fox and Ronkowski (1997) found political science students to be evenly distributed among the four learning styles that Kolb associated with his model and urged variation in instructional strategies to reach students who would otherwise find the discipline "dull, difficult, and uninteresting were it presented through only one method" (736).

Kolb's conceptualization of experiential learning has been modified to incorporate many different classroom activities. For example, Svinicki and Dixon (1987) noted that laboratories, observations, simulations, field work, films, problem sets, and reading texts are all forms of concrete experience. Student logs and journals and certain forms of small-group discussion foster reflec- tive observation. Listening to lectures, writing papers, building models, and constructing analogies draw upon abstract conceptualization skills, while doing simulations, case studies, field work, projects and homework require students to engage in active experimentation.

In addition to expanding the repertoire of pedagogical activities aimed at reaching students with diverse learning styles, experiential learning has the added value of promoting what Fink (1998) describes as "higher level learning." Fink argues that most undergraduate teaching focuses on learning as knowing (i.e., understanding and remembering content information), thinking (i.e., learning how to apply, analyze or create with information and facts), or learning how to learn

(i.e., developing the skills needed to tackle other subjects). Less common are courses that incorporate higher. level learning strategies, courses that challenge students to size up the significance of what has been learned (i.e., connecting different realms of knowledge) and to make psycho-social changes through reflection on one's self and relations with others (i.e., metacognition).

The absence of higher level learning coincides precisely with the shortcoming identified by Silverberg (1994, 718) when she criticized the mainstream approach to incorporating gender and race in political science curricula ("add women and/or Blacks and stir"). The "add and stir" approach simply treats gender and race as new content areas for students to know or to think analytically about. Because teachers fail to engage students in higher level learning of self-reflection, metacognition, and psycho-social discourse, Silverberg pointed out, they should not be surprised when only AfricanAmerican students read assigned material on race, only women read the material on gender, and white males read only the material that "[does] not include the words 'race' and 'sex' in the title" (718).

Examples of the use of experiential learning strategies in political science generally report favorable results (see LaPorte and Hadwiger 1991; Taylor 1994; Miller 1996). Closest to the project I report, Miller (1996) used hands-on analysis of newspaper stories to illustrate the invisibility of and stereotypical coverage of women in the news. Most authors have reported the benefits of active learning to energize and engage students, to "bridge the gap between theory and practice" and to develop higher order thinking skills (Bonwell and Eison 1991, 53).

\section{Teaching Gender: An Undergraduate Experience}

In the spring semester of 1997,35 upper-division undergraduates (29 women and 6 men) enrolled in Political Science 3020. The course description emphasizes the exploration of the gendered nature of leadership with a special focus on the experiences of women in leadership positions in governance. Specifically, the syllabus identifies the following questions: (1) Is leadership a culturally "gendered" concept that marginalizes women within political structures? (2) Are there fundamental social, psychological, and structural dilemmas that confront women in leadership roles? (3) Is there empirical evidence to suggest that women leaders behave in different ways than men in similar roles? In addition to the usual readings, lectures, and written assignments, the course included a field research project designed to encourage students to learn more about the gender dimensions of leadership.

The centerpiece of the course was an interview project that required students to participate in the development, design, and conduct of interviews with men and women in elected or high-level appointed positions in Oklahoma state government. The interview pool included Oklahoma state legislators elected for the first time between 1985 and 1996, district judges elected for the first 
time during the same period, and state administration officials holding political appointments in the administration of Governor Frank Keating (1994-97). In all, 96 individuals were contacted and asked to participate. Each student conducted at least two interviews and a total of 82 elected and appointed officials (45 women, $38 \mathrm{men}$ ) were interviewed. Three undergraduate research fellows of the Carl Albert Congressional Research and Studies Center assisted me in developing the list of potential interviewees, contacting officials for interviews, and handling administrative details of the project. As a result, the students in the class were required only to make two appointments and conduct the interviews. The advance work maximized participation in the project. Another Carl Albert undergraduate fellow assisted in conducting a follow-up assessment of the course that included interviews with students in the class. ${ }^{1}$

\section{The Experiential Learning Cycle}

Before actually conducting the interviews, students completed several preparatory steps outlined in Kolb's cycle of experiential learning. Following the cycle of experiential learning, students first engaged in the "concrete experience" of reading Elsa

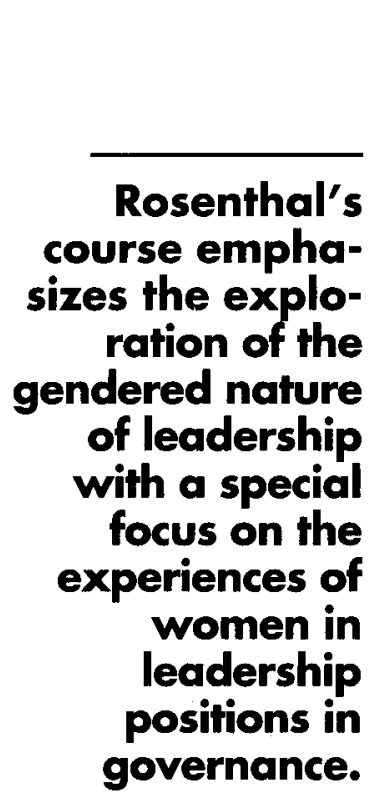

Walsh's Divided Lives (1995). The book is a popularized introduction to the philosophical construction and pragmatic dilemmas of publicprivate spheres. The book features case studies of three women and their personal struggles to balance the demands of spouse, family, and friends with high profile careers. After reading the text, students engaged in in-class discussions designed to foster "reflective observation." The students discussed the specific issues women faced when trying to balance their public and private lives and the gendered nature of work. In addition, the students critiqued the author's research methods and offered challenges to the findings. For example, students faulted Walsh's selection of only three cases (all women) and the study's acknowledged class bias to focus on women with economic independence. The critique of methods allowed students to move to the stage of "abstract conceptualization" by leading to a lecture on different epistemological approaches in the social sciences and the relative advantages of different methodological research strategies. Finally, in an activity designed to encourage "active experimentation," the students worked in small groups to develop an alternative empirical research strategy, to formulate research hypotheses, and to write items for the survey instrument. In the end, the choice of methodology was imposed by the instructor, and the rationale for the particular research design was explained after students had an opportunity to discuss various alternatives.

The project concluded with a second round of experiential learning activities. Students received training in interview techniques, role played practice interviews, and conducted their individual interviews (concrete experience). The students used Q methodology combined with more traditional open-ended questions about the personal rewards and drawbacks of public service. In $\mathrm{Q}$ methodology, interviewees are given a set of statements (29 in this case) that must be sorted into a quasinormal distribution of factors from "most or extremely important" to "least or not at all important." Officials were directed to sort the factors after being instructed:

There are many factors that a person considers before accepting a new job or role in public service. These factors involve career, fam-

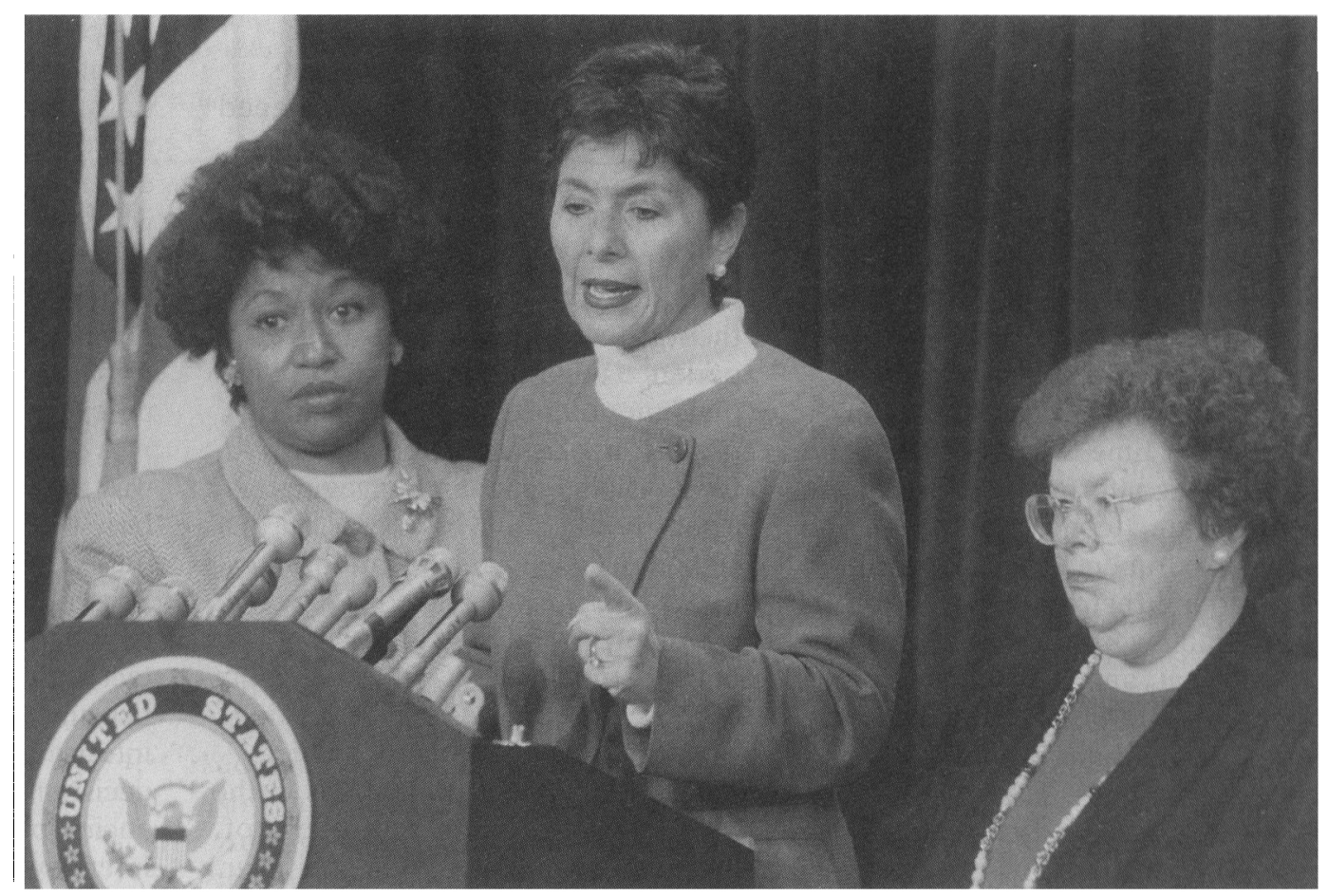

Senator Barbara Boxer (D-CA) is flanked by Senators Carol Mosely-Braun (D-IL) and Barbara Mikulski (D-MD). (Jay Mallin, Impact Visuals, 1997) 
ily, and friends. At different points in a person's life, some factors weigh more heavily than others. I want you to think of a specific and difficult decision, for example, when you first ran for elected office or considered a run for higher office. ${ }^{2}$ On these cards are printed statements that you might have considered at the time of your decision. Using the instructions on the yellow sheet, sort the cards according to their relative importance.

After the interviewees sorted the cards, the interviewers probed for explanations of the factors that figured most prominently in the person's thinking.

At the conclusion of their interviews, students were required to write a paper about their experiences guided by thought questions (reflective observation). For example:

In what ways, did your interviews confirm or refute the ideas presented in either Divided Lives or Beyond the Double Bind (Jamieson 1995)? Which of the "double binds" seemed to be most important to understanding your interview subjects' political careers?

Divided Lives used a case study approach to understanding the tension between public and private demands. Contrast that approach to the more empirical approach used in our interviews. What advantages or disadvantages do you see in each approach?

What did you like and dislike about the interview project? What particular insights do you most value from the experience?

Finally, once the preliminary data were compiled, the instructor reported the results in class and students spent time discussing the data and offering alternative interpretations (abstract conceptualization and active experimentation). Many students found their interviewees uncomfortable with the Q-sort interview format, and the students raised important questions about the data produced (and not produced) by different methods. Thus, their interview experiences led to a fruitful discussion of the limits of empirical social science methods. The activities undertaken in the course are summarized in terms of Kolb's model in Figure 1.

\section{Student Response}

Student reaction to the project was ascertained by three methods: student papers addressing the third question above, the standard university evaluation instrument, and follow-up interviews with students. Unfortunately, no preproject survey assessed student attitudes toward gender issues, so student response is primarily descriptive rather than evaluative.

In their reaction papers, students uniformly praised the interview project as a learning experience that provided important confirmation of material covered in readings and lectures. What students liked most about the interview project was that it allowed them to experience the classroom topics more concretely. As one student noted, "I was able to get a real feel for what we were studying."

A male student, who had resisted the idea that women in leadership positions faced different and tangible constraints as a result of privatesphere demands, confessed to having his mind totally changed by the interview he conducted with a highlevel female appointee in the Department of Corrections.

More than half of the students wrote that the interviews heightened their awareness of problems that women, in particular, face in leadership roles in politics and public administration. Several students commented that the project provided them with an important shared experience that led to a productive dialogue. Indeed, throughout the project, in-class discussions were lively, challenging, and engaging.

Gauged by their responses on the standard university evaluations, students' reactions to the course were extremely positive. A question asking for students "overall" assessment of the course earned a mean rating of 4.4 on a five-point scale, which placed the student evaluations in the $89^{\text {th }}$ percentile among all College of Arts and Sciences courses of similar size. When taught a year earlier without the field research project, the same course earned a mean rating of 4.1 , placing it in the $73^{\text {rd }}$ percentile among similar-sized arts and sciences courses. On an open-ended question asking about "specific strong points of the course," nine of the 23 students who offered written comments mentioned the interview project. As one student noted:

The strong point of the course was the interviews and the subsequent discussion of outcomes proving or disproving what we had read in class. This exercise was fun and I urge you to have such an exercise every chance possible. It gave me a firsthand look at the situations women face in leadership.

Another student wrote that the project "allowed the class the opportunity to learn, not just by listening to what she [the instructor] had to say, but using information gained from the class."

Similar feedback was gained in follow-up interviews conducted with the students. Students reported that the interviews they did made the class discussions more meaningful, personally and collectively. Others said they felt reassured to find that social science theory had real-life application. Students described the experience as "positive" and "unique" and valued the opportunity to speak candidly with state leaders in informal or more personal settings. As one student wrote in her reaction paper, "The value of this experience is indescribable. Speaking with public servants and leaders makes them seem more real and human. When they become real people with real struggles, we begin to have more compassion and appreciate them even more."

A secondary benefit of the project was that many students, but particularly the female students, saw their interviews as valuable mentoring. Several female students noted that they had had limited personal contact with female role models in politics and public service. Because the interviews focused on making career decisions and the dilemmas of balancing public and private lives, the interviews naturally led into discussions of the students' own aspirations. One female student who inter- 


\section{Figure 1 \\ Application of Kolb's Experiential \\ Learning Cycle to an Undergraduate Course}

\section{ACTIVE EXPERIMENTATION}

4. Students form hypotheses based on topics addressed by book and in lecture.

5. Students participate in small group discussions focused on quesiton development.

10. Students discuss the data and offer interpretaitons.

\section{CONCRETE EXPERIENCE}

1. Students read Divided Lives by Elsa Walsh.

6. Students participate in interview training and role-play practice interviews.

7. Students conduct individual interviews.
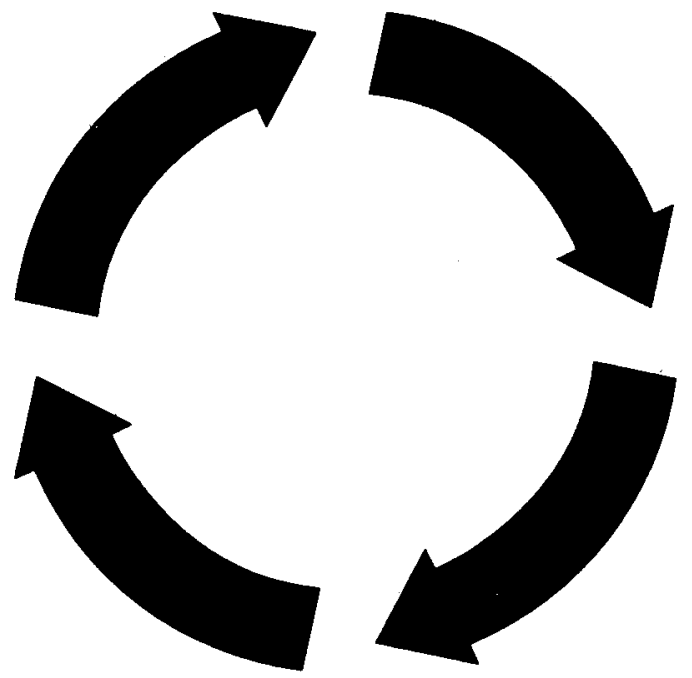

\section{ABSTRACT CONCEPTUALIZATION}

3. Instructor lectures on different epistemological approaches and research designs.

9. Students discuss the data and offer interpreations.

\section{REFLECTIVE OBSERVATION}

2. Students discuss topics addressed by the book and critique the author's methodology and findings.

8. Students write reaction papers reflecting their feelings and incorporating their findings. viewed an Oklahoma Supreme Court justice reported:

My conversation with my female interview subject was a very positive experience. We had a great conversation about life, work, and family. I have never really given much thought to "mentoring" as a concept, but I certainly learned a lot in talking with her. Not to sound cliched, it was refreshing and inspiring to get advice from someone who has some of the same basic ideas as I do. She encouraged me to trust myself and my own decisions and to not be driven by the ideas that having money and a "five-year plan" are everything.

While a positive experience, field research of this type can seem daunting since many students are not particularly proactive. The students complained of scheduling problems and expressed their general anxiety about interviewing public officials. Two missed appointments caused me some embarrassment. To insure a high level of participation, a teacher must have the resources or time to lay the groundwork for the project and be willing to do a lot of hand holding. Embarking on such a project requires planning, coordination, and administrative support that may outstrip available resources. The administrative details also limit the extent to which experiential learning can be pursued; undoubtedly a more extensive field experience of five or six interviews would have been even more beneficial for students. The logistics of a project that large are formidable, however.

\section{Conclusion}

If students are asked to consider how deeply gender is embedded in the processes, procedures, and cultures of political and governing institutions, then teachers must confront the reality that feminist theory and scholarly research will reach and resonate with only a limited number of undergraduates. Thus, teaching must be carefully crafted to make visible the dimensions of masculinism and expose the constraints on feminism in the study of politics. 
The interview project I have described represents a systematic application of Kolb's experiential learning cycle that appears to provide real advantages for teaching about gender and politics. To the extent that classroom and learning activities cause students to "experience" more directly the gendered nature of politics and political phenomenon, students can move beyond content concerns (and their resis- tance to the content) to understand the abstractions of gender and femininity and masculinity as ideological (Duerst-Lahti and Kelly 1995). A shared field experience also creates a basis for classroom dialogue that overcomes the oppositional nature of many contemporary political conversations on gender. The shared experience of the interview project had the effect of opening up classroom dialogue and discussion. More research is needed, however, to evaluate the specific effect that such a strategy may have on student attitudes. Pre- and postproject surveys of the students in conjunction with future field projects would help to confirm the initial impression that experiential learning is also effective in overcoming student resistance to using gender as an analytical concept.

\section{Notes}

1. The author wishes to acknowledge the invaluable assistance and contributions of Deneka Turney, Jana Vogt, Jodi Velasco, and Alisha Jones.
2. The lead-in statement for appointed officials asked the individual to think of a decision such as "when you took a senior man- agement or policy job that was demanding, visible, influential, and required a substantial commitment on your part."

\section{References}

Bonwell, Charles C., and James A. Eison. 1991. Active Learning: Creating Excitement in the Classroom. Washington, DC: School of Education and Human Development, George Washington University.

Duerst-Lahti, Georgia, and Rita Mae Kelly. 1995. Gender Power, Leadership, and Governance. Ann Arbor: University of Michigan Press.

Faludi, Susan. 1991. Backlash: The Undeclared War Against American Women. New York: Doubleday.

Fink, L. Dee. 1998. "Typology of Higher Level Learning." Norman: Instructional Development Program, University of Oklahoma. Manuscript.

Fox, Richard L., and Shirley A. Ronkowski. 1997. "Learning Styles of Political Science Students." PS: Political Science and Politics 30(4): 732-37.

Fox-Genovese, Elizabeth. 1996. "Feminism is not the Story of My Life": How Today's
Feminist Elite has Lost Touch with the Real Concerns of Women. New York: Nan A. Talese.

Jamieson, Kathleen Hall. 1995. Beyond the Double Bind: Women and Leadership. New York: Oxford University Press.

Kenney, Sally J. 1996. "Field Essay: New Research on Gendered Political Institutions." Political Research Quarterly 49:445-66.

Kolb, D.A. 1984. Experiential Learning: Experience as the Source of Learning and Development. Englewood Cliffs, NJ: PrenticeHall.

La Porte, Todd R., and David Hadwiger. 1991. "Teaching Public Administration through Field Research: California Agency Reconnaissance Project." PS: Political Science and Politics 24(December): 707-12.

Miller, Penny M. 1996. "Teaching Women in the News: Exposing the 'Invisible Majority'." PS: Political Science and Politics 29(September): 513-17.
Silverberg, Helene. 1994. "Organizing a Course that is Attentive to Issues of Racial and Sexual Difference." PS: Political Science and Politics 27(December): 71819.

Svinicki, Marilla D., and Nancy M. Dixon. 1987. "The Kolb Model Modified for Classroom Activities." College Teaching 35(December): 141-46.

Tannen, Deborah. 1998. The Argument Culture. New York: Random House.

Taylor, Andrew J. 1994. "Teaching Politics Panoramically: American Government and the Case Method." PS: Political Science and Politics 27(September): 535-37.

Walsh, Elsa. 1995. Divided Lives. New York: Anchor Doubleday Books.

Wood, Julia T. 1994. Gendered Lives: Communication, Gender and Culture. Belmont, CA: Wadsworth. 